\title{
Efficacy and safety of long-term insulin pump treatment in patients with type 1 diabetes aged over 50 years
} \author{
Tomasz Klupa ${ }^{1), 2)}$ \\ 1) Department of Metabolic Diseases, Jagiellonian University Medical College, Kraków, Poland \\ 2) Department of Metabolic Diseases, University Hospital, Kraków, Poland
}

Bartłomiej Matejko ${ }^{1), 2)}$, Sabina Krzyżowska ${ }^{1)}$, Beata Kieć-Wilk ${ }^{1), 2)}$, Maciej Tadeusz Malecki ${ }^{1), 2)}$ and

\begin{abstract}
Continuous subcutaneous insulin infusion (CSII) therapy using insulin pumps has become widely used in the treatment of type 1 diabetes mellitus (T1DM). This retrospective study aimed to assess the efficacy and safety of long-term insulin pump treatment in patients with T1DM aged $\geq 50$ years. The study included patients aged $\geq 50$ years, who had a diagnosis of T1DM based on clinical criteria and/or presence of autoantibodies characteristic of autoimmune diabetes, and had received $\geq 5$ years of recent and uninterrupted treatment with a personal insulin pump. We analyzed records on HbA1c levels across the entire observation period. The cohort comprised 17 patients, of whom $6(35 \%)$ were men and $11(65 \%)$ were women. The mean duration of observation was 6.6 years, during which patients had a mean of $8.4 \mathrm{HbA} 1 \mathrm{c}$ measurements. Mean $\mathrm{HbA} 1 \mathrm{c}$ level over the entire observation period was 6.7\% (range, 5.3-7.4\%). Overall, 11 patients (65\%) had mean $\mathrm{HbAlc}$ levels at the ADA-recommended target of $<7 \%$ and 5 patients $(29 \%)$ had mean $\mathrm{HbAlc}<6.5 \%$. Mean HbA1c level was significantly lower at the end of the observation period than at the start $(6.52 \%$ versus $6.91 \%$; difference, $-0.39 \% ; p<0.01)$, indicating an improvement in glycaemic control over time. On average, patients experienced one level 1 hypoglycaemia episode every 2.4 days. This retrospective analysis of at least 5 years of follow-up of selected patients with T1DM aged $\geq 50$ years at the start of observation, showed that CSII is a safe and effective treatment option in this age group.
\end{abstract}

Key words: Type 1 diabetes, Insulin pump, Elderly, Hypoglycaemia

\section{CONTINUOUS SUBCUTANEOUS INSULIN INFU-}

SION (CSII) therapy using insulin pumps has become widely used in the treatment of patients with type 1 diabetes mellitus (TIDM) [1-3]. However, very limited evidence is available concerning its efficacy and safety in selected subpopulations of adults with T1DM, such as older patients, who are particularly vulnerable to hypoglycaemia and the chronic complications of diabetes [4-7]. Older patients with T1DM are more likely than younger ones to have unidentified cognitive deficits, which may lead to difficulty in complex self-care activities, such as glucose monitoring and dose-adjustment of insulin and other drugs [8]. Nevertheless, it is widely recognized that older individuals with T1DM, who have normal cognitive ability, good physical health and relatively long life expectancy should aim for the same glycaemic targets as younger adults [8]. The studies

Submitted May 13, 2019; Accepted Dec. 30, 2019 as EJ19-0188 Released online in J-STAGE as advance publication Feb. 4, 2020 Correspondence to: Bartłomiej Matejko, Ph.D., Department of Metabolic Diseases, Jagiellonian University, 2 Macieja Jakubowskiego Street, 30-688 Kraków, Poland.

E-mail: b.matejko@yahoo.com published to date indicate good acceptance, tolerability and efficacy of CSII treatment in older patients with T1DM [4-9]. Furthermore, the 2018 American Diabetes Association (ADA) Standards of Medical Care in Diabetes clearly state that advanced age alone is not an indication to terminate CSII treatment in patients aged $>64$ years [8]. However, more data are needed to define fully the potential benefits and risks of insulin pump therapy in this age group.

The aim of this study was to retrospectively assess the efficacy and safety of long-term insulin pump treatment in patients with $\mathrm{T} 1 \mathrm{DM}$ aged $\geq 50$ years.

\section{Materials and Methods}

This was a retrospective study of patients with T1DM receiving medical care at the Department of Metabolic Diseases, University Hospital, Kraków (an academic referral centre for diabetes in southeastern Poland) or CenterMed Outpatient Clinic (a Polish private healthcare institution). We included all patients aged $>50$ years who had recently received at least 5 years of uninterrupted treatment with a personal insulin pump out of a total 
cohort of 632 patient receiving this form of therapy followed in our Department. Diagnosis of T1DM was made based on WHO criteria, presence of typical clinical symptoms and insulin therapy requirement from the beginning of the disease. Since this was a retrospective study without any action on the part of the patient, no attempt was made to obtain the consent of the bioethics committee.

All available data on glycated haemoglobin (HbA1c) levels during the entire observation period were collected from patient medical records. HbAlc levels in both centres were measured using high-performance liquid chromatography aligned with the Diabetes Control and Complications Trial standard. The data were analysed for changes in $\mathrm{HbAlc}$ and the number of patients achieving ADA glycaemic targets. Medical records were also used to acquire data on selected chronic complications of diabetes: retinopathy (all stages), peripheral neuropathy and myocardial infarction.

In addition, we collected the most recent available 14 days of data downloaded from the insulin pump and blood glucose meter. We used this data to analyze the following variables: mean blood glucose concentration from the glucose meter; mean number of blood glucose measurements per day; overall number of hypoglycaemic episodes per two weeks; mean body weight-adjusted daily insulin dose; mean percentage of total insulin dose provided by basal insulin; mean number of boluses per day; subjective hypoglycaemia perception; and use of the bolus calculator (BC) and continuous glucose monitoring system (CGMS). Clinically significant (level 2) hypoglycaemia was defined as blood glucose $<54 \mathrm{mg} / \mathrm{dL}$ (3.0 $\mathrm{mmol} / \mathrm{L}$ ), while the glucose alert value (level 1 hypoglycaemia) was defined as blood glucose $<70 \mathrm{mg} / \mathrm{dL}$ (3.9 $\mathrm{mmol} / \mathrm{L}$ ) [8]. We defined patients who administered $>50 \%$ of their daily boluses with the assistance of the BC as regular users of this function. We also defined patients with any available CGMS electrode (only Medtronic system was used) data from the 14-day period as CGMS users [10].

Differences between groups were analysed with Student's $t$ test or nonparametric tests (such as the Wilcoxon test for paired samples), as appropriate. $P$ values $<0.05$ were considered significant. All statistical analyses were conducted in SPSS Statistics software v18 (SPSS Inc., Chicago, IL, USA).

\section{Results}

The population comprised 17 patients with T1DM, of whom $6(35 \%)$ were men and $11(65 \%)$ were women. Mean ( \pm standard deviation $[\mathrm{SD}])$ age at study entry was $63.7 \pm 6.5$ years (range, 55-83) and mean $( \pm \mathrm{SD}$ ) dura- tion of T1DM was $30.1 \pm 10.1$ years (range, 13-45). Of note is that the study included an 83-year-old woman, who had had T1DM for 33 years and had received 18 years of CSII therapy. Mean $( \pm \mathrm{SD})$ body-mass index was $24.5 \pm 2.7 \mathrm{~kg} / \mathrm{m}^{2}$ (range, 19.1-28.7); none of the included patients were obese. Overall, 12 patients (70.6\%) used insulin lispro, 3 (17.6\%) used insulin aspart, 1 (5.9\%) used insulin glulisine and 1 (5.9\%) used neutral human insulin. All patients used Medtronic pumps: Paradigm Veo $(N=6 ; 35.3 \%)$; Paradigm $715(N$ $=5 ; 29.4 \%)$; Paradigm $722(N=3 ; 17.6 \%)$; Paradigm $712(N=1 ; 5.9 \%)$; Medtronic 640G $(N=1 ; 5.9 \%)$; and MiniMed $508(N=1 ; 5.9 \%)$. Clinical characteristics of the study cohort is summarized in Table 1.

The collected clinical data covered a mean duration of observation of 6.6 years, during which patients received a mean of $8.4 \mathrm{HbA1c}$ measurements. During the entire period, mean HbAlc was $6.7 \%$ (range of means, 5.3$7.4 \%)$. Eleven patients $(65 \%)$ had mean $\mathrm{HbA} 1 \mathrm{c}$ levels at the ADA-recommended target of $<7 \%$, while 5 patients (29\%) had mean HbA1c $<6.5 \%$. The last mean recorded HbA1c measurement was significantly lower than the mean first $(6.5 \%$ versus $6.9 \% ; p<0.01)$, indicating an improvement in glycaemic control over time, as illustrated by individual HbA1c level trajectories (Fig. 1). Additionally, we compared the subgroups of patients defined based on the HbA1c level ( $\leq$ and $>7 \%$ ). No difference was identified in terms of basic clinical characteristics, such as age, BMI, T1DM duration and duration of CSII use.

A total of 4 patients $(23.5 \%)$ used the CGMS and 11 $(64.7 \%)$ used the BC on a regular basis. CGMS users had lower mean $\mathrm{HbA} 1 \mathrm{c}$ than the rest of the group $(6.2 \%$ versus $6.9 \% ; p=0.029)$ but there was no difference in $\mathrm{HbA} 1 \mathrm{c}$ between patients who regularly used the $\mathrm{BC}$ and those who did not $(6.4 \%$ versus $6.9 \% ; p=0.323)$. Overall, the mean percentage of the total daily insulin dose provided by basal insulin was more than $40 \%$ (mean [ \pm $\mathrm{SD}], 44.6 \pm 8.5 \%$ ) and the mean $( \pm \mathrm{SD})$ body weightadjusted insulin dose was $0.5( \pm 0.1) \mathrm{IU} / \mathrm{kg}$. The SD of blood glucose measurements was small (mean, 54 $\mathrm{mg} / \mathrm{dL}$ ) and less than half the value of the mean blood glucose level. On average, patients experienced one level 1 hypoglycaemic episode every 2.4 days and one level 2 hypoglycaemic episode every 7.7 days. None of the patients included in the study reported any significant hypoglycaemia with loss of consciousness and/or need of help from another person.

\section{Discussion}

Evidence to date regarding the efficacy of CSII in older patients with T1DM has been very limited and is 
Table 1 Clinical characteristics of the study cohort

\begin{tabular}{lcc}
\hline Parameter & Mean \pm SD & Median (range) \\
\hline Data from medical records & & \\
\hline Age *, years & $63.65 \pm 6.46$ & $65.00(55.0-83.00)$ \\
Duration of diabetes *, years & $30.12 \pm 10.09$ & $31.00(13.5-45.0)$ \\
Duration of CSII *, years & $11.38 \pm 5.10$ & $11.50(1-21)$ \\
Body-mass index *, kg/m² & $24.54 \pm 2.66$ & $24.73(19.05-28.67)$ \\
HbA1c \#, \% & $6.71 \pm 0.59$ & $6.87(5.31-7.40)$ \\
\hline Insulin pump download data & & \\
Mean blood glucose concentration, mg/dL & $137.53 \pm 17.22$ & $136(101-166)$ \\
SD of blood glucose concentrations, mg/dL & $54.75 \pm 18.43$ & $54(24-89)$ \\
Mean number of blood glucose measurements per day, $N$ & $5.49 \pm 2.02$ & $5(2-10)$ \\
Mean daily insulin dose, IU & $41.65 \pm 14.01$ & $37(21-66)$ \\
Mean body weight-adjusted insulin dose, IU/kg & $0.51 \pm 0.13$ & $0.5(0.34-0.73)$ \\
Mean percentage of total insulin dose provided by basal insulin, $\%$ & $44.60 \pm 8.53$ & $46(29-61)$ \\
Mean number of boluses per day, $N$ & $6.26 \pm 2.70$ & $6(3-11)$ \\
Level 1 hypoglycemia episodes per two weeks, $N$ & $5.81 \pm 5.71$ & $5(0-20)$ \\
Level 2 hypoglycemia episodes per two weeks, $N$ & $1.81 \pm 3.63$ & $0(0-12)$ \\
\hline
\end{tabular}

CSII, continuous subcutaneous insulin infusion; HAlc; glycated hemoglobin; SD, standard deviation, * at the end of the observation, \# the mean value across the observation period.

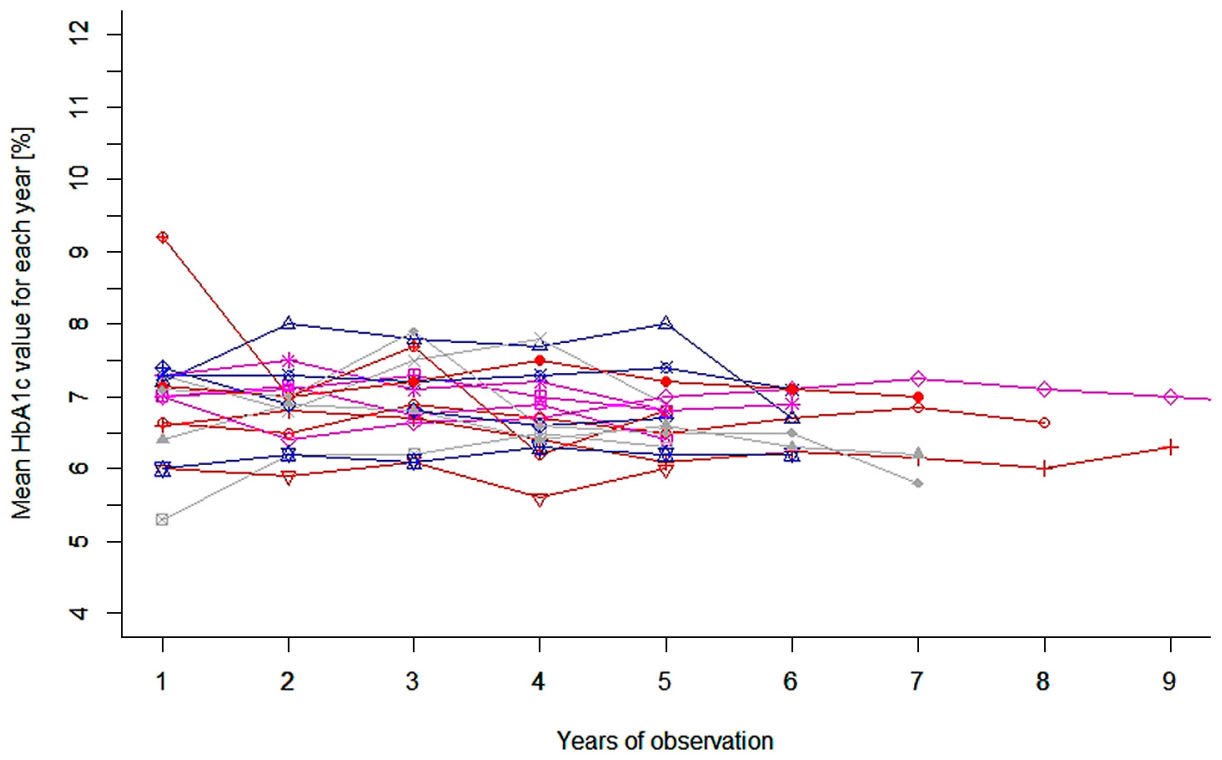

Fig. 1 HbA1c trajectory for each patient

based mainly on cross-sectional, observational studies of between 5 and 57 patients [7]. Compared with multipledaily injection therapy, use of CSII in older patients has been linked with better glycaemic outcomes, albeit at the cost of a small increase in healthcare resource utilisation [7].

In this retrospective analysis, we show that CSII treat- ment in selected older patients (aged $\geq 50$ years) with T1DM may be safe and effective over at least 5 years of follow-up. Of note, glycaemic control, as reflected in HbAlc level, did not deteriorate and actually improved over the period of observation. This finding contrasts sharply with recent results from the T1D Exchange registry where, in adolescents and young adults with T1DM, 
mean HbA1c increased between 2010-2012 and 20162018, despite an increase in insulin pump and CGMS use [11]. Moreover, the excellent glycaemic control in our cohort was attained with relatively few hypoglycaemic episodes, as evidenced by analysis of the most recent available insulin pump download data. Of note, the hypoglycaemia frequency in the study population and in the larger cohort of patients followed in our Department and characterised by $\mathrm{HbAlc}<7 \%$, were comparable [10]. The present cohort showed better glycaemic control compared with the overall population of patients with T1DM in our department, which mostly comprises younger patients of a similar age to those in the T1D Exchange registry $[10,11]$. Furthermore, the proportion of patients attaining target $\mathrm{HbAlc}$ level $(<7 \%)$ in our study was greater than in the subgroup of patients aged $>50$ years in the T1D Exchange registry $(65 \%$ versus $27 \%)$ [11].

Several factors may account for these differences. First, the average age at diagnosis of T1DM in our cohort was $>30$ years, which is relatively late for this type of diabetes. T1DM that presents later in life may be associated with a slower rate of autoimmune beta-cell destruction and greater residual endogenous insulin secretion [12]. Compared with T1DM patients without measurable C-peptide levels, those with preserved residual endogenous insulin secretion have been shown to have more favorable treatment outcomes [13]. However, we were not able to perform C-peptide measurements to further evaluate whether this factor might account for the differences between our study and previous analyses $[5$, 7].

Secondly, personal insulin pumps are reimbursed in Poland only for patients aged up to 26 years. Because our older patients had to bear the cost of pumps and related supplies themselves, they may represent a more highly motivated patient population.

Thirdly, patient education and attitudes to selfmanagement probably vary according to age. Older individuals usually take greater responsibility for themselves and generally have more time available to spend on diabetes self-management, and they might choose to devote to more educational sessions both before and after CSII initiation. It has recently been emphasised that, when discussing diabetes self-management, we should consider a patient's developmental stage, competing demands (such as work and family), psychosocial adjustments, and the potential burden of comorbidities [14].

Of note, we showed that patients who used CGMS ( $N$ $=4$ ) had better glycaemic control, compared with those who did not, which was consistent with prior data from observational and randomized trial in patients aged $>60$ (65) years [15-17].

In addition, our cohort included an 83-year-old woman who had had T1DM for 33 years and who had received CSII therapy for 18 years (mean HbA1c during an observation period was $6.7 \%$ ). To our knowledge, this patient is the oldest reported user of CSII, and highlights that even very advanced age need not preclude attainment of excellent glycaemic control with CSII therapy.

Among the shortcomings of this observational retrospective analysis, one should probably mention the lack of a control group of T1DM patients on multiple daily injections (MDI). However, this group of authors has under their medical care almost entirely T1DM patients on CSII; thus, selecting a control group of T1DM on MDI was not possible.

Of note, this study includes no judgement about possible CSII superiority over MDI in this T1DM age group. Additionally, we did not use the age 65 years, mentioned in the 2018 American Diabetes Association Standards, to define the study group; however, not enough T1DM patients above this age remained under our medical care to present an extended follow-up for them. There were no data on hypoglycaemia classified as being night or daytime available for this cohort which was another limitation of our study.

\section{Conclusions}

Our retrospective analysis of at least 5 years of followup in selected patients with T1DM aged $\geq 50$ years at the start of observation shows that CSII is a safe and effective option in this age group.

\section{Funding}

N/A.

\section{Author Disclosure Statement}

No competing financial interests exist.

\section{References}

1. Misso ML, Egberts KJ, Page M, O'Connor D, Shaw J (2010) Continuous subcutaneous insulin infusion (CSII) versus multiple insulin injections for type 1 diabetes melli- tus. Cochrane Database Syst Rev CD005103.

2. Pickup JC, Sutton AJ (2008) Severe hypoglycaemia and glycaemic control in type 1 diabetes: meta-analysis of 
multiple daily insulin injections compared with continuous subcutaneous insulin infusion. Diabet Med 25: 765-774.

3. Lukács A, Kiss-Tóth E, Varga B, Soós A, Takác P, et al. (2013) Benefits of continuous subcutaneous insulin infusion on quality of life. Int $J$ Technol Assess Health Care 29: 48-52.

4. Boulet G, Halpern EM, Lovblom LE, Weisman A, Bai JW, et al. (2016) Prevalence of insulin pump therapy and its association with measures of glycemic control: results from the Canadian study of longevity in type 1 diabetes glycaemic. Diabetes Technol Ther 18: 298-307.

5. Matejko B, Cyganek K, Katra B, Galicka-Latala D, Grzanka M, et al. (2011) Insulin pump therapy is equally effective and safe in elderly and young type 1 diabetes patients. Rev Diabet Stud 8: 254-258.

6. Yeoh E, Beato-Vibora P, Rogers H, Amiel SA, Choudhary P (2015) Efficacy of insulin pump therapy in elderly patients. Diabetes Technol Ther 17: 364-365.

7. Briganti EM, Summers JC, Fitzgerald ZA, Lambers LNJ, Cohen ND (2018) Continuous subcutaneous insulin infusion can be used effectively and safely in older patients with type 1 diabetes: long-term follow-up. Diabetes Technol Ther 20: 783-786.

8. American Diabetes Association. Standards of Medical Care (2017) Diabetes Care 40 (Suppl. 1).

9. Beato-Víbora P, Yeoh E, Rogers H, Hopkins D, Amiel SA, et al. (2015) Sustained benefit of continuous subcutaneous insulin infusion on glycaemic control and hypoglycaemia in adults with Type 1 diabetes. Diabet Med 32: 1453-1459.
10. Matejko B, Skupien J, Mrozińska S, Grzanka M, Cyganek $\mathrm{K}$, et al. (2015) Factors associated with glycemic control in adult type 1 diabetes patients treated with insulin pump therapy. Endocrine 48: 164-169.

11. Foster NC, Beck RW, Miller KM, Clements MA, Rickels MR, et al. (2019) State of type 1 diabetes management and outcomes from the T1D Exchange in 2016-2018. Diabetes Technol Ther 21: 66-72.

12. Poudel A, Savari O, Striegel DA, Periwal V, Taxy J, et al. (2015) Beta-cell destruction and preservation in childhood and adult onset type 1 diabetes. Endocrine 49: 693-702.

13. (1998) Effect of intensive therapy on residual beta-cell function in patients with type 1 diabetes in the diabetes control and complications trial. A randomized, controlled trial. The Diabetes Control and Complications Trial Research Group. Ann Intern Med 128: 517-523.

14. McCarthy MM, Grey M (2018) Type 1 diabetes selfmanagement from emerging adulthood through older adulthood. Diabetes Care 41: 1608-1614.

15. Slattery D, Choudhary P (2017) Clinical use of continuous glucose monitoring in adults with type 1 diabetes. Diabetes Technol Ther 19: 55-61.

16. Argento NB, Nakamura K (2014) Personal real-time continuous glucose monitoring in patients 65 years and older. Endocr Pract 20: 1297-1302.

17. Ruedy KJ, Parkin CG, Riddlesworth TD, Graham C (2017) DIAMOND Study Group. Continuous glucose monitoring in older adults with type 1 and type 2 diabetes using multiple daily injections of insulin: results from the DIAMOND trial. J Diabetes Sci Technol 11: 1138-1146. 